\title{
Oral Administration of Alkylglycerols Differentially Modulates High-Fat Diet-Induced Obesity and Insulin Resistance in Mice
}

\author{
Mingshun Zhang, ${ }^{1,2}$ Shuna Sun, ${ }^{3}$ Ning Tang, ${ }^{1}$ Wei Cai, ${ }^{1,4}$ and Linxi Qian ${ }^{1,4}$ \\ ${ }^{1}$ Xinhua Hospital, Shanghai Institute for Pediatric Research, Shanghai Jiao Tong University, School of Medicine, \\ Shanghai 200092, China \\ ${ }^{2}$ Department of Immunology, Nanjing Medical University, Nanjing 210029, China \\ ${ }^{3}$ Fudan Children's Hospital, Fudan University, School of Medicine, Shanghai 201102, China \\ ${ }^{4}$ Shanghai Key Laboratory of Pediatric Gastroenterology and Nutrition, Shanghai 200092, China
}

Correspondence should be addressed to Wei Cai; caiw204@yahoo.com.cn and Linxi Qian; microtuble@gmail.com

Received 1 January 2013; Accepted 5 June 2013

Academic Editor: Wei Jia

Copyright (C) 2013 Mingshun Zhang et al. This is an open access article distributed under the Creative Commons Attribution License, which permits unrestricted use, distribution, and reproduction in any medium, provided the original work is properly cited.

\begin{abstract}
Alkylglycerols (AKGs) from shark liver oil (SLO) were demonstrated to have strong potency to stimulate immune response. However, no study has been conducted on the effects of AKGs on diet-induced obesity and metabolic inflammatory disorder. The purpose of the present study was to investigate the effect of two AKGs isoforms on obesity and insulin resistance in mice fed highfat (HF) diet. Forty-eight C57BL/6 mice were divided into normal, HF, HF + $20 \mathrm{mg} / \mathrm{kg}$ selachyl alcohol (SA), HF + $200 \mathrm{mg} / \mathrm{kg} \mathrm{SA}$, $\mathrm{HF}+20 \mathrm{mg} / \mathrm{kg}$ batyl alcohol (BA), and HF $+200 \mathrm{mg} / \mathrm{kg}$ BA groups. Body weight, fasting glucose, lipids, insulin and leptin levels, serum IL-1 $\beta$, and TNF- $\alpha$ levels were compared among different groups. Our results showed that high-dose SA decreased body weight, serum triglyceride, cholesterol, fasting glucose level, insulin level, and serum leptin level of the HF fed mice, while highdose BA increased fasting insulin level of the HF fed mice. Pretreatment of primary adipocytes with $10 \mu \mathrm{M}$ SA or BA differentially modulates LPS-mediated MAPK and NF- $\kappa$ B signaling. Our study demonstrated that oral administration of AKGs has differential effects on HF-induced obesity and metabolic inflammatory disorder in mice.
\end{abstract}

\section{Introduction}

Obesity has become a common public health issue with a cluster of metabolic abnormalities. The incidence of obesityrelated chronic diseases is increasing rapidly worldwide [1]. Evidence has accumulated indicating that obesity is closely associated with a state of systematic, low-grade inflammation characterized by activation of inflammatory signaling pathways and abnormal cytokine production in adipose tissue $[2,3]$. The cytokines produced by adipocytes include several inflammatory markers such as interleukin (IL)-6, tumor necrosis factor (TNF)- $\alpha$, and monocyte chemoattractant protein (MCP)-1 [4]. These cytokines are elevated in patients with obesity and insulin resistance and are highly associated with the development of cardiovascular diseases and type 2 diabetes mellitus.
Recently, dietary supplements have been used for prevention of obesity and diabetes mellitus due to their high compliance and low toxicity. Shark liver oil (SLO), a wellknown dietary supplement, contains alkylglycerols (AKGs), squalene, and essential fatty acids [5]. It has recently been shown that SLO has various pharmacological benefits such as chemoprotective properties against reactive oxygen species as well as anti-inflammatory, antibacterial, antifungal, and anticancer potency [6]. AKGs, the major component of SLO, are glycerol ether lipids that have structural characteristics of an ether linkage between fatty acid and $\alpha$-position of the glycerol backbone. According to the fatty acid chain length and the number of double bonds, several derivatives of AKGs have been identified. They include such substances as batyl alcohol (BA), chimyl alcohol (CA), and selachyl alcohol (SA) [7]. SA, the predominant component of bioactive AKGs in the 
SLO (accounting for 59.4\%), contains an unsaturated bond in the long hydrocarbon chain (18C:1). CA and BA, which are saturated in their hydrocarbon chains (16C:0 CA, 18C:0 BA), account for a minor proportion of SLO (9.1\% CA, 2.8\% BA) [6]. AKGs are also found in immune organs such as bone marrow and spleen, indicating their important role in human immune activity [8]. AKGs mainly function by stimulating immune response to enhance the human defense against inflammation [9]. AKGs can also be applied to treat leukemia and solid tumor as well [10]. It was demonstrated that AKGs can inhibit the growth, vascularization, and dissemination of lung carcinoma tumors in mice $[11,12]$.

The antidiabetic effects of various bioactive food components have gained widespread attention. However, it was also demonstrated that some nutrients such as selenium have side-effect on energy metabolism if they are supplemented inappropriately [13]. AKGs have been shown to have capability of activating cytotoxic macrophages leading to an enhanced phagocytosis and elevating Th-1 cytokines such as TNF- $\alpha$ which are required for macrophage activation [14]. Adipose tissue macrophages play a key role in obesityinduced inflammation and insulin resistance [15]. However, no study has been conducted on the effects of AKGs on dietinduced obesity and metabolic inflammatory disorder. It is interesting to explore how AKGs affect energy metabolism if consumed daily as a nutrition supplement. Therefore, we examined the effect of AKGs on lipopolysaccharide- (LPS-) mediated insulin resistance and induction of inflammatory genes in high-fat (HF) fed mice.

\section{Materials and Methods}

2.1. Chemicals. SA was purchased from NIKKO Chemicals (Tokyo, Japan). BA was purchased from Bachem (Bubendorf, Switzerland). Escherichia coli LPS 0111:B6 was purchased from Sigma-Aldrich (St. Louis, MO). Glucose, cholesterol, and triglyceride kits were obtained from Kinghawk Pharmaceutical (Beijing, China). Insulin, leptin, IL-1 $\beta$, and TNF$\alpha$ ELISA kits were purchased from R\&D systems (Minneapolis, MN). Antiphospho- (Thr183/Tyr185) and total JNK, antiphospho- (Thr202/Tyr204) and total ERK, and anti-I $\kappa$ B $\alpha$ were purchased from Santa Cruz (Santa Cruz, CA). All other chemical reagents used in the present study were of analytical grade.

2.2. Animals and Facilities. The study was approved by the Animal Ethics Committee of Xinhua Hospital. Forty-eight, 4-week old male C57BL/6 mice were purchased from SLAC Laboratories (Shanghai, China). All mice were housed in stainless steel cages with bedding ( 6 mice/cage). Sufficient bedding was used to keep mice dry and clean. All the mice were exposed to a 12-hour light and dark cycle. Frequent bedding changes and cage cleaning were performed as often as necessary.

2.3. Animal Study Design. After arrival, mice were acclimatized for 4 days. After acclimatation, forty-eight mice were randomly divided into six groups of 8 mice each. Both normal chow and high-fat diets were purchased from Shanghai Slac Laboratory Animal Co., Ltd. Normal chow diets contained $20.5 \%$ crude protein, $4.62 \%$ crude fat, $52.5 \%$ nitrogen-free extract, and $4.35 \%$ crude fibers (total calories $3.45 \mathrm{Kcal} / \mathrm{g}, 12 \%$ calories in fat). High-fat diets contained $18.8 \%$ crude protein, $16.2 \%$ crude fat, $45.2 \%$ nitrogen-free extract, and $3.98 \%$ crude fibers (total calories $3.79 \mathrm{Kcal} / \mathrm{g}$, 38\% calories in fat) [16]. For 8 weeks, groups 1 and 2 received the normal diets (ND) and high-fat diets (HF), respectively; groups 3 and 4 were fed the HF supplemented with 20 and $200 \mathrm{mg} / \mathrm{kg} \mathrm{SA}$, respectively; groups 5 and 6 were fed the HF supplemented with 20 and $200 \mathrm{mg} / \mathrm{kg} \mathrm{BA}$, respectively. Body weight was monitored weekly. At the end of the experiment, blood samples were collected after overnight fasting. Following 4 days recovery, all groups were fasted for 5 hours and then challenged with $100 \mathrm{ng}$ LPS intraperitoneally. After 2 hours, animals were then euthanized and blood samples, liver, and epididymal fat were collected. Liver tissues and visceral adipose were immediately weighted after removal [17]. Serum was isolated by centrifugation at $1500 \mathrm{~g}$ at $4^{\circ} \mathrm{C}$ for $10 \mathrm{~min}$ and stored at $-80^{\circ} \mathrm{C}$ until it was used for blood biochemical assays.

2.4. Culturing of Primary Adipocytes. Abdominal white adipose tissue was obtained from 4- to 5-week-old, wildtype mice. After blood washing, the adipose tissues were minced and digested with $1 \mathrm{mg} / \mathrm{mL}$ collagenase type I (SigmaAldrich, St. Louis, MO) for $30 \mathrm{~min}$ at $37^{\circ} \mathrm{C}$. Cells were filtered through $200-\mu \mathrm{m}$ pore size nylon meshes. The stromal vascular cells (SVCs) were separated from adipocytes by centrifugation and washed with DMEM (Invitrogen, Carlsbad, CA) supplemented with 10\% fetal bovine serum (FBS). SVCs were plated and propagated to confluence in DMEM supplemented with $10 \% \mathrm{FBS}, 50 \mu \mathrm{g} / \mathrm{mL}$ streptomycin, and $50 \mathrm{U} / \mathrm{mL}$ penicillin [18]. After attachment, the medium was replaced by induction medium containing $10 \mu \mathrm{g} / \mathrm{mL}$ insulin (INS), $1 \mu \mathrm{m}$ dexamethasone (DEX), and $0.5 \mathrm{~mm} 3$-isobutyl-1methylxanthine (MIX) with 10\% FBS and continued differentiation for 12 days. On day 12, cultures were pretreated with DMSO vehicle, or different concentrations of SA or BA for $24 \mathrm{hrs}$, and then treated with $10 \mu \mathrm{g} / \mathrm{L}$ LPS for $6 \mathrm{hrs}$.

2.5. Immunoblotting Analysis. Following treatment, cultures were harvested and protein was extracted with RIPA buffer. Immunoblotting analysis was performed as described previously [19].

2.6. Biochemical Analysis. Concentrations of insulin, leptin, IL- $1 \beta$, and TNF- $\alpha$ were measured using ELISA kit. Glucose, total cholesterol, and triglyceride were tested using enzymatic methods. Homeostatic Model Assessment-Insulin Resistance (HOMA-IR) was calculated from glucose and insulin concentrations (fasting glucose $(\mathrm{mmol} / \mathrm{L}) \times$ fasting insulin $(\mu \mathrm{U} / \mathrm{mL}) / 22.5)$ [20].

2.7. Statistical Analysis. Data are shown as means with their standard errors. Statistical significance was evaluated using one-way ANOVA followed by Duncan's multiple range test. $P$ value $<0.05$ was considered statistically significant. 


\section{Results}

3.1. Effects of AKGs Diets on Body and Organ Weights. Daily food intake during the experimental period was not significantly different among groups. No changes of end-point body weight and net weight gain were observed between $\mathrm{HF}$ diet group and low-dose $(20 \mathrm{mg} / \mathrm{kg}$ ) AKGs (SA or BA) supplemented groups during the 60 -day period. High-dose SA $(200 \mathrm{mg} / \mathrm{kg})$ supplementation significantly decreased the end-point body weight and net weight gain of the HF fed mice during the 60-day dietary intervention. Weights of epididymal white adipose tissue and liver were compared among the different dietary treatments. Epididymal fat was significantly decreased as percent body weight in mice that received $200 \mathrm{mg} / \mathrm{kg}$ SA supplementation (Table 1).

3.2. Effects of AKGs Diets on Serum Triglyceride and Cholesterol. There was a significant $(110 \%)$ increase in the serum triglyceride level of the HF group compared with the ND group, whereas a $25 \%$ decrease of serum triglyceride was observed in the $200 \mathrm{mg} / \mathrm{kg} \mathrm{SA}$ group relative to the HF group $(P<0.01)$ (Figure 1(a)). HF feeding caused a significant $(50 \%)$ increase in the total cholesterol level. $200 \mathrm{mg} / \mathrm{kg} \mathrm{SA}$ treatment; however, had reduced the serum cholesterol level by $30 \%$ as compared to the HF group $(P<0.001)$ (Figure 1(b)). There was no significant difference in triglyceride or cholesterol level between the HF group and the HF plus low-dose SA group. No significant change in triglyceride or cholesterol level was observed in HF plus BA diet group as compared with HF group.

3.3. Effects of AKGs Diets on Glucose, Insulin, and HOMA-IR. To investigate the impact of different AKGs supplemented $\mathrm{HF}$ diets in comparison with HF diet on glucose metabolism, we examined blood glucose concentrations before and after LPS challenge in different dietary groups. HF diet group had significantly higher fasting blood glucose concentration as compared to ND diet group $(9.84 \mathrm{mmol} / \mathrm{L}$ versus $7.62 \mathrm{mmol} / \mathrm{L} ; P<0.001$ ) (Table 2). Fasting blood glucose was significantly lower in mice fed HF diet plus 20 or $200 \mathrm{mg} / \mathrm{kg}$ SA than that in mice fed $\operatorname{HF}$ diet $(P<0.001)$. After intraperitoneal injection of LPS, a drop of blood glucose concentration was observed in all groups. HF diet plus $200 \mathrm{mg} / \mathrm{kg}$ SA caused lower blood glucose concentration after LPS challenge as compared to HF diet group $(5.05 \mathrm{mmol} / \mathrm{L}$ versus $5.71 \mathrm{mmol} / \mathrm{L} ; P<0.05$ ) (Table 2 ).

The impact of different forms of AKGs on insulin resistance induced by HF diet was also assessed. The plasma insulin concentrations were examined before and after LPS challenge in different dietary groups. As expected, HF diet group had significantly higher fasting insulin concentrations as compared to ND diet group $(27.81 \mu \mathrm{IU} / \mathrm{mL}$ versus $13.49 \mu \mathrm{IU} / \mathrm{mL} ; P<0.001$ ) (Table 2 ). It was noted that fasting insulin concentration was decreased in mice fed $\mathrm{HF}$ diet plus $200 \mathrm{mg} / \mathrm{kg} \mathrm{SA}$ relative to mice fed $\mathrm{HF}$ diet $(20.92 \mu \mathrm{IU} / \mathrm{mL}$ versus $27.81 \mu \mathrm{IU} / \mathrm{mL} ; P<0.05)$, whereas insulin concentration was increased in mice fed HF diet plus $200 \mathrm{mg} / \mathrm{kg}$ BA $(P<0.05)$. After intraperitoneal injection of

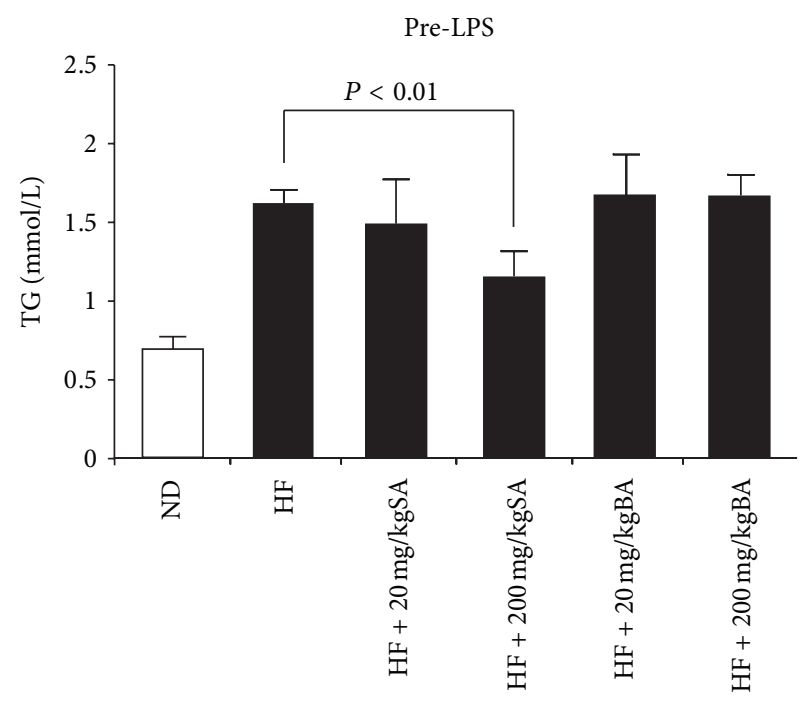

(a)

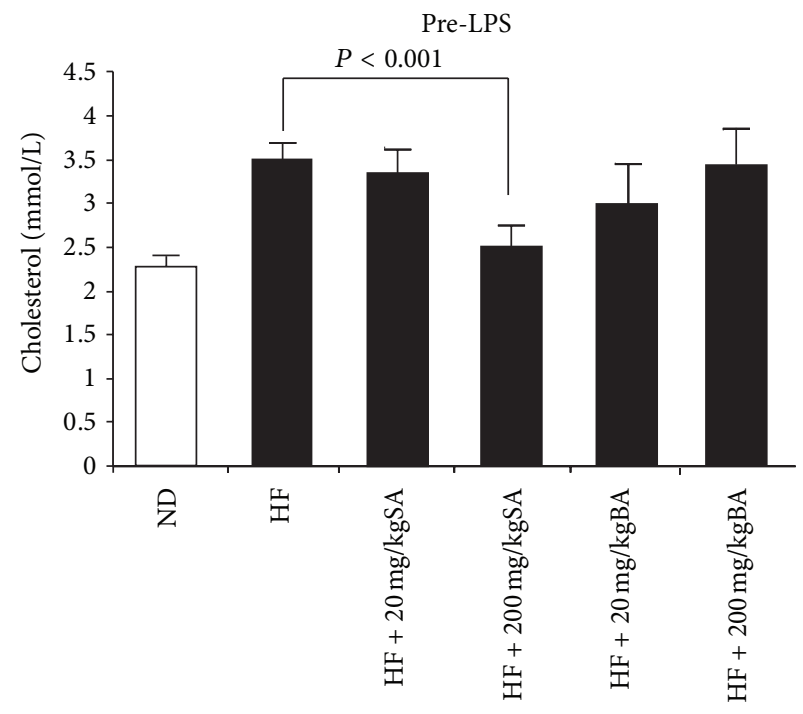

(b)

FIgURE 1: The effect of selachyl alcohol (SA) or batyl alcohol (BA) supplementation on serum triglycerides (a) and cholesterol (b). Data were presented as mean \pm SE. Significant differences were tested with two-way ANOVA. Only significant comparisons are presented.

LPS, mice fed HF plus $200 \mathrm{mg} / \mathrm{kg}$ SA showed lower insulin increase compared to mice fed HF diet $(22.92 \mu \mathrm{IU} / \mathrm{mL}$ versus $37.13 \mu \mathrm{IU} / \mathrm{mL} ; P<0.05$ ). No effects of low-dose AKGs (SA or BA) supplementation were observed on fasting insulin concentrations at pre- and post-LPS challenge (Table 2). The HOMA-IR score was calculated from fasting blood glucose and insulin concentration to assess whether AKGs diet protected mice from insulin resistance. In fact, mice that received 20 or $200 \mathrm{mg} / \mathrm{kg}$ SA supplementation had significantly lower HOMA-IR scores $(P<0.001)$, however, mice received $200 \mathrm{mg} / \mathrm{kg}$ BA supplementation had significantly higher HOMA-IR scores as compared to mice that received HF diet at pre-LPS challenge $(P<0.05)$. After intraperitoneal injection of LPS, only $200 \mathrm{mg} / \mathrm{kg}$ SA supplementation showed 


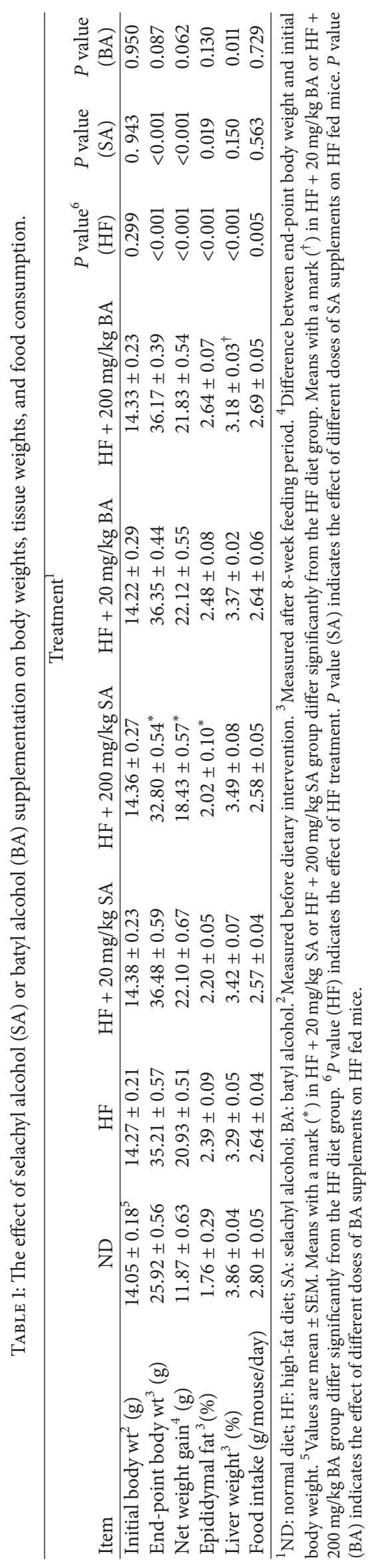


significant protective effect on insulin resistance which was indicated by HOMA-IR scores $(P<0.005)$ (Table 2$)$.

3.4. Effect of AKGs on Serum Cytokines and Leptin. The proinflammatory cytokines such as IL-1 $\beta$ and TNF- $\alpha$ were elevated after LPS challenge. Interestingly, high-dose SA or BA showed differential effects on serum IL-1 $\beta$ and TNF- $\alpha$ production after $100 \mathrm{ng}$ LPS challenge (Table 3). $200 \mathrm{mg} / \mathrm{kg}$ SA supplementation suppressed serum IL-1 $\beta$ and TNF- $\alpha$ level induced by LPS challenge $(P<0.05)$, whereas $200 \mathrm{mg} / \mathrm{kg}$ BA supplementation significantly enhanced serum IL- $1 \beta$ and TNF$\alpha$ level induced by LPS challenge $(P<0.05)$. However, there was no significant effect on IL- $1 \beta$ and TNF- $\alpha$ response to LPS challenge by low-dose AKGs (SA or BA) supplementation.

As for serum leptin, mice that received HF diet had significantly higher serum leptin concentration compared to those received ND diet $(16.55 \mathrm{ng} / \mathrm{mL}$ versus $7.26 \mathrm{ng} / \mathrm{mL}$; $P<0.05)$. We found that serum leptin concentration was significantly decreased in mice that received $200 \mathrm{mg} / \mathrm{kg} \mathrm{SA}$ supplementation as compared to mice that received HF diet at pre-LPS challenge $(13.57 \mathrm{ng} / \mathrm{mL}$ versus $16.55 \mathrm{ng} / \mathrm{mL} ; P<$ 0.05) (Table 3).

3.5. Effect of AKGs on LPS-Mediated MAPK and NF- $K B$ Activation. Given the role of MAPK pathway in inducing inflammatory gene expression via Toll-like-receptor(TLR-) 4 activation, we examined the effects of AKGs on MAPK phosphorylation. Pretreatment of mice adipocyte cultures with $10 \mu \mathrm{M}$ SA modestly decreased LPS-mediated phosphorylation of JNK and ERK (Figure 2). However, pretreatment of mice adipocyte cultures with $10 \mu \mathrm{M}$ BA increased LPS-mediated phosphorylation of JNK and ERK. In the absence of LPS, AKGs treatment did not enhance the MAPK activation. Because the activation of NF- $\kappa$ B also plays a crucial role in the transcriptional activation of inflammation-responsive genes, the effects of AKGs on NF$\kappa \mathrm{B}$ activation were examined by detecting $\mathrm{I} \kappa \mathrm{B} \alpha$ degradation via immunoblot. We found that the pretreatment with SA attenuated $\mathrm{I} \kappa \mathrm{B} \alpha$ degradation by LPS (Figure 2). However, BA did not present effect on LPS-induced NF- $\kappa \mathrm{B}$ activation in our experiments.

\section{Discussion}

SLO has been widely used in the past years in the Scandinavian medicine because of its properties as immunity boosters and a remedy against radiation therapy and cancer [21]. AKGs are the major components in SLO which could stimulate immunity both in vitro and in vivo $[22,23]$. Daily consumption of AKGs-rich SLO showed benefits to the immune system. Despite widespread intake of AKGs, safety studies on AKGs extract were poor. The acute and repeated (28 days) oral toxicity has been evaluated for oral AKGs administration in rats at doses of 200 and 1000 times the maximum recommended dose in humans [24]. In that study, AKGs administration showed no adverse effects on mortality at either acute or subchronic dose. However, the correlation between long-term AKGs supplement and HFinduced obesity has not been shown. In previous studies, AKGs were demonstrated to have potency to activate cytotoxic macrophages and increase humoral immune response [22]. AKGs could also stimulate the IL-12 and IFN-gamma production and elicit Th1 response [25, 26]. As we know, adipose infiltrated macrophage and secreted cytokines play important roles in obesity and insulin resistance [27-29]. Thus, the potency of AKGs to stimulate immunity spurred our interest to examine the AKGs effect on HF-induced obesity and insulin resistance.

Studies have shown that HF diets induce adipose tissue inflammation and stimulate TLR-4 expression [30]. TLR4, a subclass of the TLR family, plays a critical role in activating innate immune and inflammation response in mammals by recognizing bacterial LPS [31, 32]. Activation of TLR-4 in adipocytes leads to the activation of MAPK and NF- $\kappa \mathrm{B}$ signaling pathways, and induction of many inflammatory cytokines $[33,34]$. These cytokines are involved in inducing glucose intolerance, insulin resistance, and infiltration of macrophages into adipose tissue. Recent study showed that TLR-4 responds to nonbacterial ligands such as fatty acids [35-37]. It was demonstrated that saturated fatty acids such as lauric acid and palmitic acid are able to induce cyclooxygenase-2 (COX-2) expression; however, unsaturated fatty acids such as docosahexaenoic acid (DHA) and eicosapentaenoic acid (EPA) are able to inhibit saturated fatty acid-induced COX-2 expression [38]. In present study, we demonstrated that AKGs with saturated chain increased LPS-mediated activation of the MAPK signaling, which could cause the expression of inflammatory genes and insulin resistance in adipocytes. AKGs with unsaturated chain decreased LPS-mediated activation of the MAPK and NF- $\kappa$ B signaling, thus ameliorated insulin resistance. However, both AKGs with saturated and unsaturated chain did not activate MAPK or NF- $\kappa$ B signaling in the absence of LPS. Accordingly, it was indicated that both AKGs with saturated chain and unsaturated chain modulated TLR- 4 signaling and insulin response in the hyperinflammatory environment such as high-fat diet feeding or LPS treatment but did not show direct effect in the hypoinflammatory environment. This result was also noticed by Ocaña et al., who showed that BA activated the expression of IL- $1 \beta$ and IL- 6 genes only in TNF- $\alpha$-induced adipocytes but not in the nonstimulated cells [39].

Several studies have demonstrated that different forms of AKGs have differential biological effects. The unsaturated AKGs with 16 or 18 carbon alkyl chains showed strong anti-tumor and antimetastasis activities in mice model [40]. By contrast, the saturated AKGs with 16 or 18 carbon alkyl chains showed less antitumor effect or even tumorpromoting activity. Previous studies also demonstrated that proinflammatory responses were enhanced by most saturated fatty acids but reduced by most unsaturated fatty acids. In metabolic experiments, rats fed saturated fatty acids had higher triacylglycerol, cholesterol, and low-density lipoprotein cholesterol, whereas rats fed unsaturated fatty acids had lower triacylglycerol, cholesterol, and low-density lipoprotein cholesterol as compared with control rats [41, 42]. Moreover, the increased ratio of $\mathrm{P} / \mathrm{S}$ (polyunsaturated/saturated) fatty 


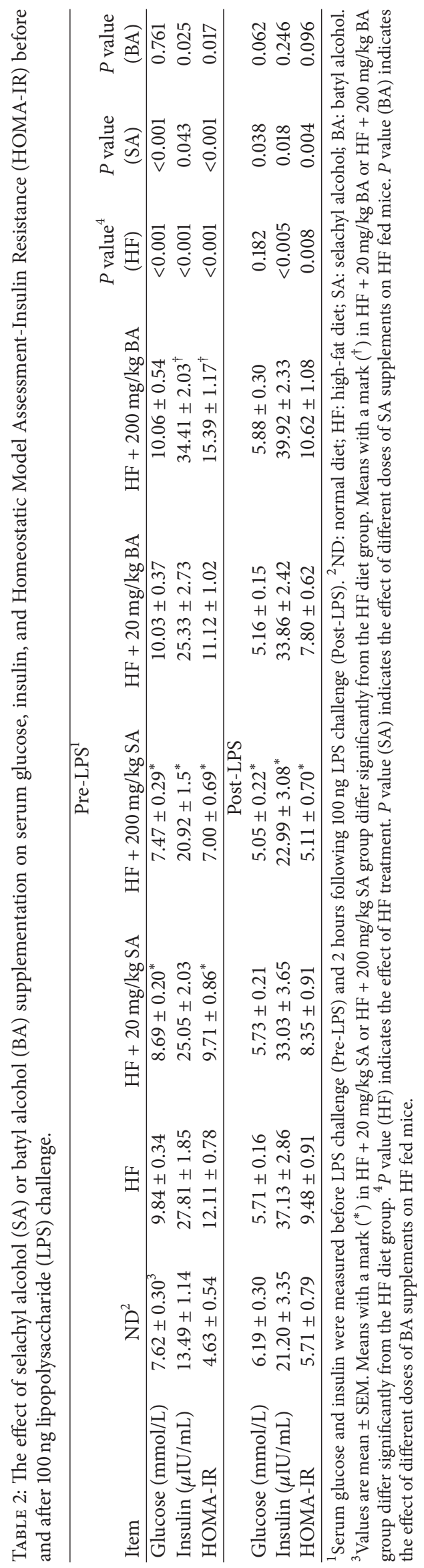




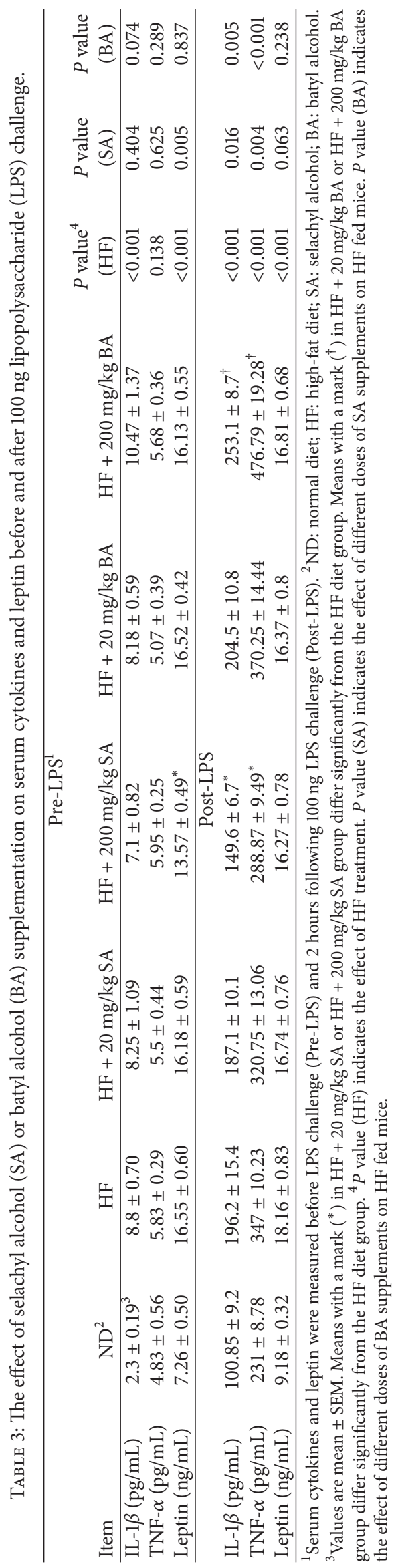




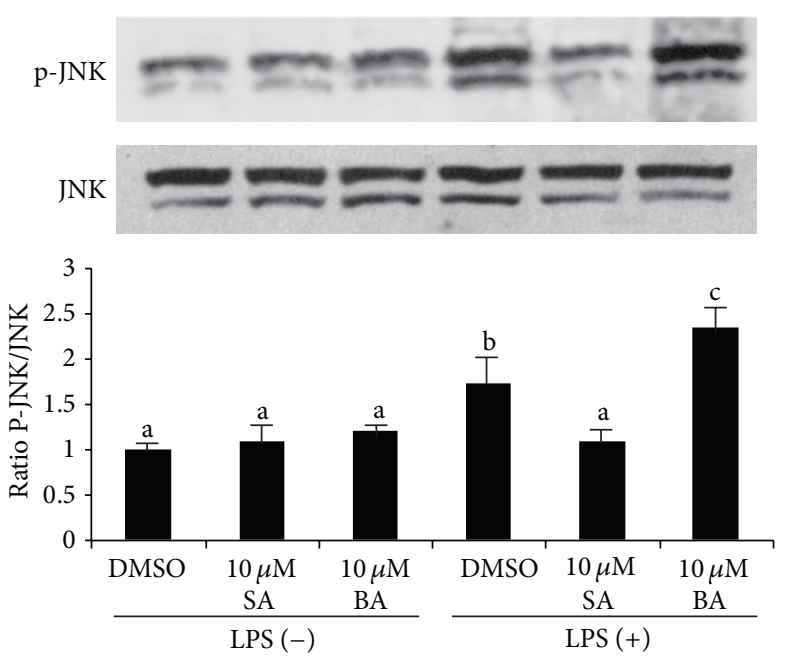

(a)
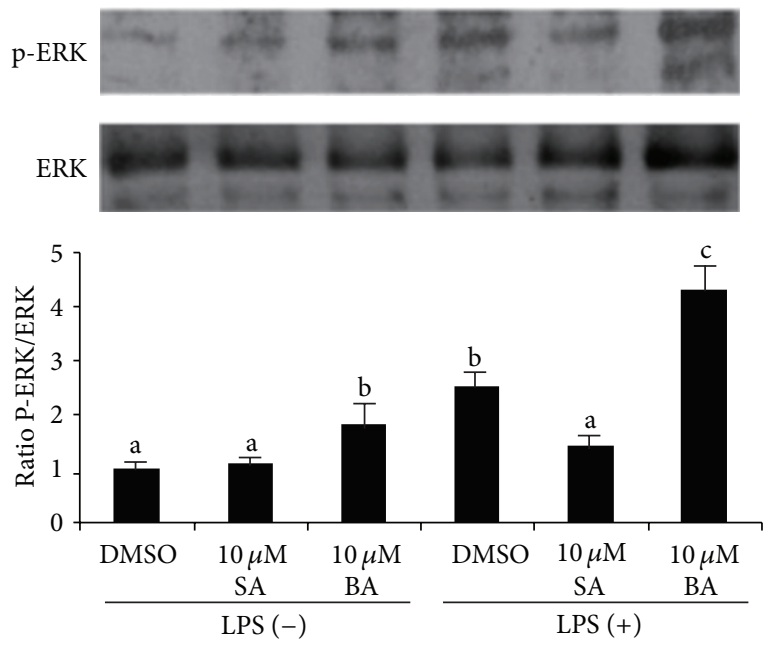

(b)

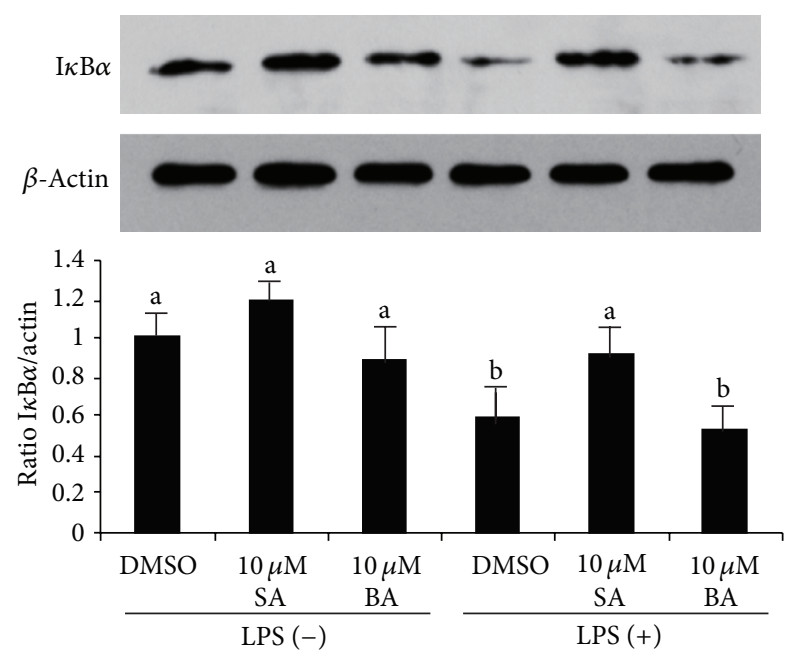

(c)

FIGURE 2: The effect of selachyl alcohol (SA) or batyl alcohol (BA) on TLR-4 signaling activated by LPS in mice primary adipocytes. Newly differentiated cells were pretreated with DMSO vehicle (-) or $10 \mu \mathrm{M} \mathrm{SA}$ or $10 \mu \mathrm{M}$ BA for $24 \mathrm{~h}$ and then treated with $10 \mu \mathrm{g} / \mathrm{L}$ LPS for $6 \mathrm{~h}$. (a) Phosphorylation of JNK (P-JNK-to-JNK ratio). (b) Phosphorylation of ERK (P-ERK-to-ERK ratio). (c) Expression of I $\kappa \mathrm{B} \alpha$ (I $\kappa \mathrm{B} \alpha$-to-actin ratio). Levels of protein were measured by western blotting. Data are a mean of $\pm \mathrm{SE}$ and corrected for loading. Significant differences between each group are indicated by different letters.

acids was beneficial in depleting white adipose tissue accumulation and improved the metabolic status in diet-induced obese hamster [43]. The controlled clinical trials have also indicated that replacing saturated fat with unsaturated fat was more effective in lowering risk of metabolic disorder than simply reducing total fat consumption [44, 45]. Our studies showed that AKGs had the similar effects on metabolic and inflammatory status as free fatty acids in spite of their ether bond with glycerol. As we know, SLO and human breast milk are both good sources of AKGs, with unsaturated forms as the predominant components. In clinical studies, SLO showed beneficial effect on lipid metabolism in patients with hypertension [46]. Breast milk has also been demonstrated to be protective against the development of childhood overweight and obesity [47]. Thus, we postulated that the predominant unsaturated AKGs in SLO and breast milk would neutralize the adverse effects of saturated AKGs on metabolism and play a prominent role of preventing metabolic syndrome.

Increasing studies have indicated that dietary supplementation of oils extracted from marine species can alter the metabolic and immunologic status which is highly associated with the incidence of obesity and type 2 diabetes. Different marine oils have distinct lipid profiles, which result in potential differences in their effects on inflammation and metabolism. Fish oil, the typical marine oil product, was demonstrated to have protective effect on LPSinduced inflammation and insulin resistance [17]. It was also shown that dietary fish oil supplementation could reduce body weight gain in HF-induced obese mice [48]. The anti-inflammation and antiobesity effects of fish oil were attributed to its richness of $(n-3)$ PUFA [49]. SLO, which was also rich of $(n-3)$ PUFA, was known to contain high 
proportion of squalene and AKGs. Both squalene and AKGs have potent immunological activity, thus eliciting people's interest of investigating their impact on metabolic balance. Squalene has already been demonstrated to be able to elevate the body weight and serum cholesterol in high-fat fed hamsters due to its involvement in hepatic cholesterol metabolism [50]. However, little is known about the association between AKGs intake and metabolic alteration. Our results showed that AKGs differentially modulated HF-induced obesity and insulin resistance in mice, which gave us indication that more attention should be paid to the impact of these immunestimulating chemicals on metabolism.

Actually, it has already been noticed that oral SLO intake has adverse effect on liver function if supplemented at high dosage [51]. Therefore, it is important to use AKGs in animal experiment at the dosage comparable to that of human supplementation for nutritional purpose. The Biomare Immuno which is manufactured by Hankintatukku (Finland) contains $60 \mathrm{mg}$ AKGs per capsule. On the label, it recommends six capsules daily, which equals to $7.2 \mathrm{mg} \mathrm{AKGs} / \mathrm{kg}^{\text {weight }}$ $\left(60 \mathrm{mg} \times 6 / 50 \mathrm{~kg}^{\text {weight }}\right)$ provided that a male adult weighs $50 \mathrm{~kg}$ on average. In the present study, AKGs at $20 \mathrm{mg} / \mathrm{kg}^{\text {diet }}$ and $200 \mathrm{mg} / \mathrm{kg}^{\text {diet }}$ dietary supplementation corresponded to $4 \mathrm{mg} / \mathrm{kg}^{\text {weight }}\left(20 \mathrm{mg} / \mathrm{kg}^{\text {diet }} \times 0.005 \mathrm{~kg}^{\text {diet }} / 0.025 \mathrm{~kg}^{\text {weight }}\right)$ and $40 \mathrm{mg} / \mathrm{kg}^{\text {weight }}\left(200 \mathrm{mg} / \mathrm{kg}^{\text {diet }} \times 0.005 \mathrm{~kg}^{\text {diet }} / 0.025 \mathrm{~kg}{ }^{\text {weight }}\right)$, respectively, assuming that a male adult mouse weighs $25 \mathrm{~g}$ and expends $5 \mathrm{~g}$ diet on average. Thus, the amount of $20 \mathrm{mg} / \mathrm{kg}^{\text {diet }}$ AKGs dietary supplement was comparable to that commonly consumed by a SLO-supplement consumer. The results obtained from rodents showed that the $20 \mathrm{mg} / \mathrm{kg}^{\text {diet }}$ dietary AKGs supplementation did not have significant effect on body weight but only showed minor effect on glucose metabolism. Nevertheless, $200 \mathrm{mg} / \mathrm{kg}^{\text {diet }}$ dietary AKGs supplementation showed obvious effects not only on body weight but also on lipid, glucose metabolism, and pro-inflammatory cytokine production. Although these results were not directly applicable to humans, they provided some implications for individuals who routinely consume AKGs supplement or AKGs-rich SLO. Taken together, our results provided novel insights into differential effects of saturated- and unsaturated-chain AKGs on adipose tissue inflammation, which suggested that routine consumption of SLO consisting of different isoforms of AKGs is safe at normal dosage and shows balanced effect on obesity and insulin resistance.

\section{Conclusion}

Collectively, these data demonstrate that the unsaturated AKGs (SA) have potency to decrease the HF-induced obesity at high dosage and ameliorate insulin resistance at normal or high dosage. The saturated AKGs (BA) can increase insulin resistance at high dosage. Our data also suggest that AKGs show differential effects on LPS-induced inflammation in adipocytes. The effect of SLO rich for AKGs on adipose metabolism and insulin response should be evaluated in the future, to warrant supplementing SLO products at a safe dosage and prevent its potential hazardous effects on metabolism.

\section{Abbreviations}

$\begin{array}{ll}\text { AKGs: } & \text { alkylglycerols } \\ \text { SA: } & \text { Selachyl alcohol } \\ \text { BA: } & \text { Batyl alcohol } \\ \text { HF: } & \text { High fat } \\ \text { ND: } & \text { Normal diets } \\ \text { LPS: } & \text { Lipopolysaccharides } \\ \text { IL: } & \text { Interleukin } \\ \text { TNF: } & \text { Tumor necrosis factor } \\ \text { SLO: } & \text { Shark liver oil } \\ \text { SVCs: } & \text { Stromal vascular cells } \\ \text { HOMA-IR: } & \text { Model assessment-insulin resistance } \\ \text { TLR: } & \text { Toll-like-receptor } \\ \text { PUFAs: } & \text { Polyunsaturated fatty acids. }\end{array}$

\section{Acknowledgments}

This research was supported by Grants 81000242, 30901472, 30772270, and 30972427 from the National Natural Science Foundation of China (to Linxi Qian, Wei Cai, and Shuna Sun), Program for Innovative Research Team of Shanghai Municipal Education Commission (to Wei Cai), 11QA1405400 Hesper Foundation of Shanghai Scientific Bureau (to Linxi Qian), 2010Y157 Junior Scientist Foundation of Shanghai Health Bureau (to Linxi Qian), and 11DZ2260500 Shanghai Key Laboratory of Pediatric Gastroenterology and Nutrition (to Wei Cai).

\section{References}

[1] H. Tilg and A. R. Moschen, "Adipocytokines: mediators linking adipose tissue, inflammation and immunity," Nature Reviews Immunology, vol. 6, no. 10, pp. 772-783, 2006.

[2] H. Xu, G. T. Barnes, Q. Yang et al., "Chronic inflammation in fat plays a crucial role in the development of obesity-related insulin resistance," Journal of Clinical Investigation, vol. 112, no. 12, pp. 1821-1830, 2003.

[3] H. Wu, S. Ghosh, X. D. Perrard et al., "T-cell accumulation and regulated on activation, normal $\mathrm{T}$ cell expressed and secreted upregulation in adipose tissue in obesity," Circulation, vol. 115, no. 8, pp. 1029-1038, 2007.

[4] G. S. Hotamisligil, "Inflammation and metabolic disorders," Nature, vol. 444, no. 7121, pp. 860-867, 2006.

[5] C. G. Bordier, N. Sellier, A. P. Foucault, and F. le Goffic, "Purification and characterization of deep sea shark Centrophorus squamosus liver oil 1-O-alkylglycerol ether lipids," Lipids, vol. 31, no. 5, pp. 521-528, 1996.

[6] T. Iannitti and B. Palmieri, "An update on the therapeutic role of alkylglycerols," Marine Drugs, vol. 8, no. 8, pp. 2267-2300, 2010.

[7] A. Brohult, J. Brohult, and S. Brohult, "Biochemical effects of alkoxyglycerols and their use in cancer therapy," Acta chemica Scandinavica, vol. 24, no. 2, p. 730, 1970.

[8] B. Hallgren, A. Niklasson, G. Ställberg, and H. Thorin, "On the occurrence of 1-O-alkylglycerols and 1-O-(2methoxyalkyl)glycerols in human colostrum, human milk, cow's milk, sheep's milk, human red bone marrow, red 
cells, blood plasma and a uterine carcinoma," Acta chemica Scandinavica B, vol. 28, no. 9, pp. 1029-1034, 1974.

[9] D. G. Osmond, P. J. Roylance, A. J. Webb, and J. M. Yoffey, “The action of batyl alcohol and selachyl alcohol on the bone marrow of the guinea pig," Acta haematologica, vol. 29, pp. 180-186, 1963.

[10] P. Langen, H. Brachwitz, and J. Schildt, "Inhibition of proliferation of Ehrlich ascites carcinoma cells in vitro and in vivo by halogeno analogues of long chain acyl- and alkylglycerols," Acta Biologica et Medica Germanica, vol. 38, no. 7, pp. 965-974, 1979.

[11] F. Pédrono, B. Martin, C. Leduc et al., "Natural alkylglycerols restrain growth and metastasis of grafted tumors in mice," Nutrition and Cancer, vol. 48, no. 1, pp. 64-69, 2004.

[12] E. Skopińska-Rózewska, J. Chorostowska-Wynimko, M. Krotkiewski et al., "Inhibitory effect of Greenland shark liver oil combined with squalen and arctic birch ashes on angiogenesis and L-1 sarcoma growth in Balb/c mice," Polish Journal of Veterinary Sciences, vol. 6, supplement 3, pp. 54-56, 2003.

[13] M.-S. Zeng, X. Li, Y. Liu et al., "A high-selenium diet induces insulin resistance in gestating rats and their offspring," Free Radical Biology and Medicine, vol. 52, no. 8, pp. 1335-1342, 2012.

[14] W. E. Berdel, W. R. Bausert, and H. U. Weltzien, "The influence of alkyl-lysophospholipids and lysophospholipidactivated macrophages on the development of metastasis of 3Lewis lung carcinoma," European Journal of Cancer and Clinical Oncology, vol. 16, no. 9, pp. 1199-1204, 1980.

[15] E. Ortega Martinez de Victoria, X. Xu, J. Koska et al., "Macrophage content in subcutaneous adipose tissue: associations with adiposity, age, inflammatory markers, and wholebody insulin action in healthy pima Indians," Diabetes, vol. 58, no. 2, pp. 385-393, 2009.

[16] W. Xie, D. Gu, J. Li, K. Cui, and Y. Zhang, "Effects and action mechanisms of berberine and rhizoma coptidis on gut microbes and obesity in high-fat diet-fed C57BL/6J mice," PLoS One, vol. 6, no. 9, Article ID e24520, 2011.

[17] M. Vijay-Kumar, S. M. Vanegas, N. Patel, J. D. Aitken, T. R. Ziegler, and V. Ganji, "Fish oil rich diet in comparison to saturated fat rich diet offered protection against lipopolysaccharideinduced inflammation and insulin resistance in mice," Nutrition and Metabolism, vol. 8, no. 1, article 16, 2011.

[18] M. Masaki, T. Kurisaki, K. Shirakawa, and A. Sehara-Fujisawa, "Role of meltrin $\alpha$ (ADAM12) in obesity induced by high-fat diet," Endocrinology, vol. 146, no. 4, pp. 1752-1763, 2005.

[19] D. Hwang, B. C. Jang, G. Yu, and M. Boudreau, "Expression of mitogen-inducible cyclooxygenase induced by lipopolysaccharide: mediation through both mitogen-activated protein kinase and NF- $\kappa \mathrm{B}$ signaling pathways in macrophages," Biochemical Pharmacology, vol. 54, no. 1, pp. 87-96, 1997.

[20] M. J. Holness, G. K. Greenwood, N. D. Smith, and M. C. Sugden, "PPAR $\alpha$ activation and increased dietary lipid oppose thyroid hormone signaling and rescue impaired glucose-stimulated insulin secretion in hyperthyroidism," American Journal of Physiology-Endocrinology and Metabolism, vol. 295, no. 6, pp. E1380-E1389, 2008.

[21] A. Brohult, J. Brohult, S. Brohult, and I. Joelsson, "Effect of alkoxyglycerols on the frequency of fistulas following radiation therapy for carcinoma of the uterine cervix," Acta Obstetricia et Gynecologica Scandinavica, vol. 58, no. 2, pp. 203-207, 1979.

[22] S. Homma, I. Millman, and N. Yamamoto, "A serum factor for macrophage activation after in vitro dodecylglycerol treatment of mouse lymphocytes," Immunology and Cell Biology, vol. 68, part 2, pp. 137-142, 1990.
[23] S. Y. Oh and L. S. Jadhav, "Effects of dietary alkylglycerols in lactating rats on immune responses in pups," Pediatric Research, vol. 36, no. 3, pp. 300-305, 1994.

[24] A. Anadón, M. A. Martínez, I. Ares et al., "Acute and repeated dose (28 days) oral safety studies of an alkoxyglycerol extract from shark liver oil in rats," Journal of Agricultural and Food Chemistry, vol. 58, no. 3, pp. 2040-2046, 2010.

[25] P. Lewkowicz, M. Banasik, E. Głowacka, N. Lewkowicz, and H. Tchórzewski, "Effect of high doses of shark liver oil supplementation on $\mathrm{T}$ cell polarization and peripheral blood polymorphonuclear cell function," Polski Merkuriusz Lekarski, vol. 18, no. 108, pp. 686-692, 2005.

[26] R. Ziegler, W. Jobst, H. Minne, and J. D. Faulhaber, "Calciotropic hormones and lipolysis of human adipose tissue: role of extracellular calcium as conditioning but not regulating factor," Endokrinologie, vol. 75, no. 1, pp. 77-88, 1980.

[27] M. E. Rausch, S. Weisberg, P. Vardhana, and D. V. Tortoriello, "Obesity in C57BL/6J mice is characterized by adipose tissue hypoxia and cytotoxic T-cell infiltration," International Journal of Obesity, vol. 32, no. 3, pp. 451-463, 2008.

[28] J. Jager, T. Grémeaux, M. Cormont, Y. le Marchand-Brustel, and J.-F. Tanti, "Interleukin- $\beta$-induced insulin resistance in adipocytes through down-regulation of insulin receptor substrate-1 expression," Endocrinology, vol. 148, no. 1, pp. 241251, 2007.

[29] G. S. Hotamisligil, D. L. Murray, L. N. Choy, and B. M. Spiegelman, "Tumor necrosis factor $\alpha$ inhibits signaling from the insulin receptor," Proceedings of the National Academy of Sciences of the United States of America, vol. 91, no. 11, pp. 48544858, 1994.

[30] E. Gäbele, K. Dostert, C. Dorn, E. Patsenker, F. Stickel, and C. Hellerbrand, "A new model of interactive effects of alcohol and high-fat diet on hepatic fibrosis," Alcoholism, vol. 35, no. 7, pp. 1361-1367, 2011.

[31] B. Beutler, "Inferences, questions and possibilities in Toll-like receptor signalling," Nature, vol. 430, no. 6996, pp. 257-263, 2004.

[32] S. Akira, "Toll-like receptors and innate immunity," Advances in Immunology, vol. 78, pp. 1-56, 2001.

[33] E. Faure, L. Thomas, H. Xu, A. E. Medvedev, O. Equils, and M. Arditi, "Bacterial lipopolysaccharide and IFN- $\gamma$ induce tolllike receptor 2 and toll-like receptor 4 expression in human endothelial cells: role of NF- $\kappa$ B activation," Journal of Immunology, vol. 166, no. 3, pp. 2018-2024, 2001.

[34] M. J. Song, K. H. Kim, J. M. Yoon, and J. B. Kim, "Activation of Toll-like receptor 4 is associated with insulin resistance in adipocytes," Biochemical and Biophysical Research Communications, vol. 346, no. 3, pp. 739-745, 2006.

[35] D. Hwang, "Modulation of the expression of cyclooxygenase2 by fatty acids mediated through Toll-like receptor 4 -derived signaling pathways," The FASEB Journal, vol. 15, no. 14, pp. 25562564, 2001.

[36] J. Y. Lee, K. H. Sohn, S. H. Rhee, and D. Hwang, "Saturated fatty acids, but not unsaturated fatty acids, induce the expression of cyclooxygenase-2 mediated through Toll-like receptor 4," Journal of Biological Chemistry, vol. 276, no. 20, pp. 1668316689, 2001.

[37] J. Y. Lee, A. Plakidas, W. H. Lee et al., "Differential modulation of Toll-like receptors by fatty acids: preferential inhibition by n3 polyunsaturated fatty acids," Journal of Lipid Research, vol. 44, no. 3, pp. 479-486, 2003. 
[38] S. A. Lee, H. J. Kim, K. C. Chang et al., "DHA and EPA down-regulate COX-2 expression through suppression of NF$\kappa \mathrm{B}$ activity in LPS-treated human umbilical vein endothelial cells," Korean Journal of Physiology and Pharmacology, vol. 13, no. 4, pp. 301-307, 2009.

[39] A. Ocaña, C. Gómez-Asensio, E. Arranz-Gutiérrez, C. Torres, F. J. Señoráns, and G. Reglero, "In vitro study of the effect of diesterified alkoxyglycerols with conjugated linoleic acid on adipocyte inflammatory mediators," Lipids in Health and Disease, vol. 9, article 36, 2010.

[40] A.-L. Deniau, P. Mosset, F. Pédrono, R. Mitre, D. le Bot, and A. B. Legrand, "Multiple beneficial health effects of natural alkylglycerols from shark liver oil," Marine Drugs, vol. 8, no. 7, pp. 2175-2184, 2010.

[41] N. W. Chang and P. C. Huang, "Effects of the ratio of polyunsaturated and monounsaturated fatty acid to saturated fatty acid on rat plasma and liver lipid concentrations," Lipids, vol. 33, no. 5, pp. 481-487, 1998.

[42] Y. S. Diniz, A. C. Cicogna, C. R. Padovani, L. S. Santana, L. A. Faine, and E. L. B. Novelli, "Diets rich in saturated and polyunsaturated fatty acids: metabolic shifting and cardiac health," Nutrition, vol. 20, no. 2, pp. 230-234, 2004.

[43] F.-H. Liao, T.-H. Liou, W.-C. Chiu, M.-J. Shieh, and Y.-W. Chien, "Differential effects of high MUFA with high or low $\mathrm{P} / \mathrm{S}$ ratio (polyunsaturated to saturated fatty acids) on improving hepatic lipolytic enzymes and mediating PPAR $\gamma$ related with lipoprotein lipase and hormone-sensitive lipase of white adipose tissue in diet-induced obese hamster," International Journal of Obesity, vol. 34, no. 11, pp. 1608-1617, 2010.

[44] F. B. Hu, J. E. Manson, and W. C. Willett, "Types of dietary fat and risk of coronary heart disease: a critical review," Journal of the American College of Nutrition, vol. 20, no. 1, pp. 5-19, 2001.

[45] J. Salmerón, F. B. Hu, J. E. Manson et al., "Dietary fat intake and risk of type 2 diabetes in women," American Journal of Clinical Nutrition, vol. 73, no. 6, pp. 1019-1026, 2001.

[46] A. V. Pogozheva, S. A. Derbeneva, N. V. Anykina et al., "The clinical and experimental research of metabolic effects of shark liver oil," Voprosy Pitaniia, vol. 76, no. 6, pp. 28-32, 2007.

[47] C. McCrory and R. Layte, "Breastfeeding and risk of overweight and obesity at nine-years of age," Social Science and Medicine, vol. 75, no. 2, pp. 323-330, 2012.

[48] T. Mori, H. Kondo, T. Hase, I. Tokimitsu, and T. Murase, "Dietary fish oil upregulates intestinal lipid metabolism and reduces body weight gain in C57BL/6J mice," Journal of Nutrition, vol. 137, no. 12, pp. 2629-2634, 2007.

[49] F. Belzung, T. Raclot, and R. Groscolas, "Fish oil n-3 fatty acids selectively limit the hypertrophy of abdominal fat depots in growing rats fed high-fat diets," American Journal of Physiology-Regulatory Integrative and Comparative Physiology, vol. 264, no. 6, part 2, pp. R1111-R1118, 1993.

[50] Z. Zhang, W. K. Yeung, Y. Huang, and Z.-Y. Chen, "Effect of squalene and shark liver oil on serum cholesterol level in hamsters," International Journal of Food Sciences and Nutrition, vol. 53, no. 5, pp. 411-418, 2002.

[51] S. Kilincalp, M. Deveci, O. Basar, F. Ekiz, S. Coban, and O. Yuksel, "Shark liver oil: hidden dangers," Annals of Hepatology, vol. 11, no. 5, pp. 728-730. 


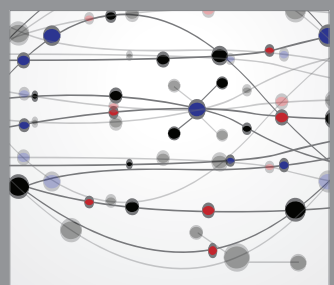

The Scientific World Journal
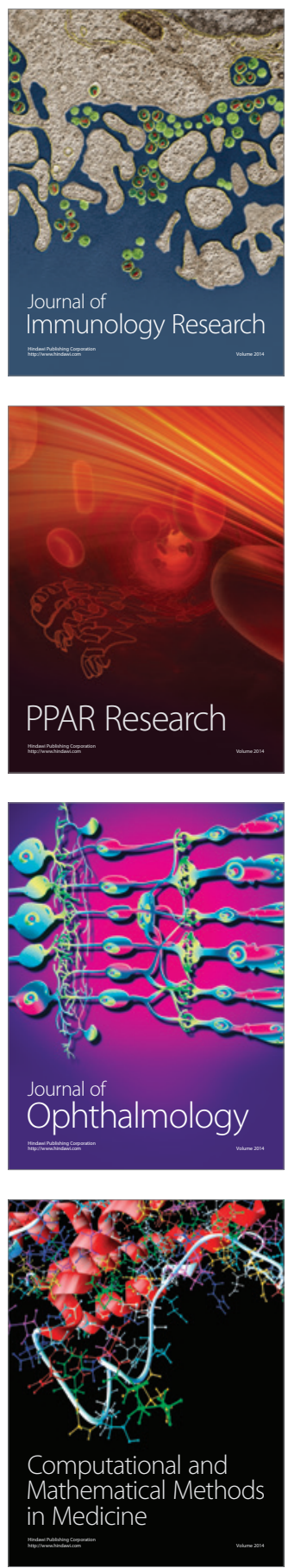

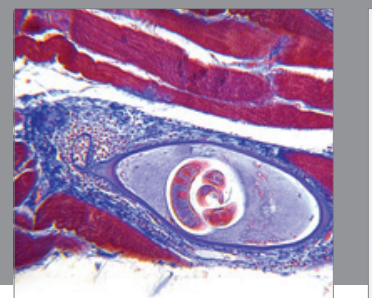

Gastroenterology

Research and Practice
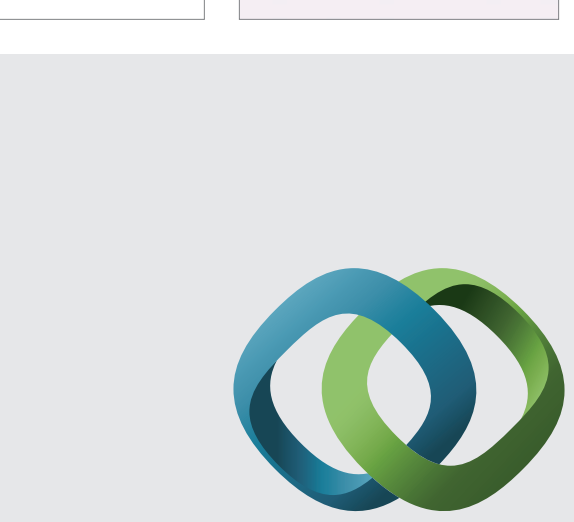

\section{Hindawi}

Submit your manuscripts at

http://www.hindawi.com
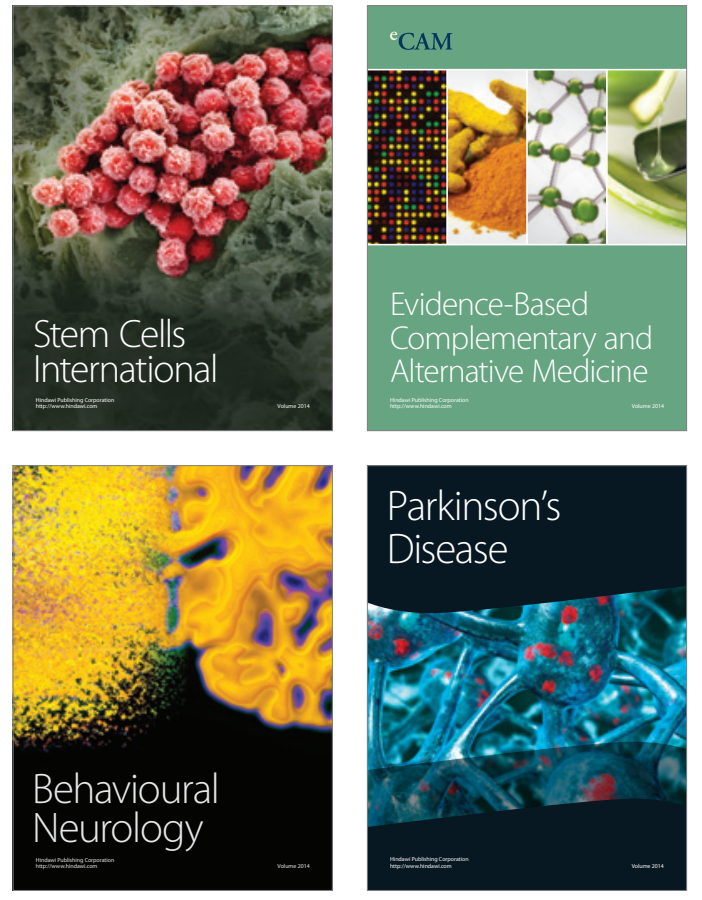
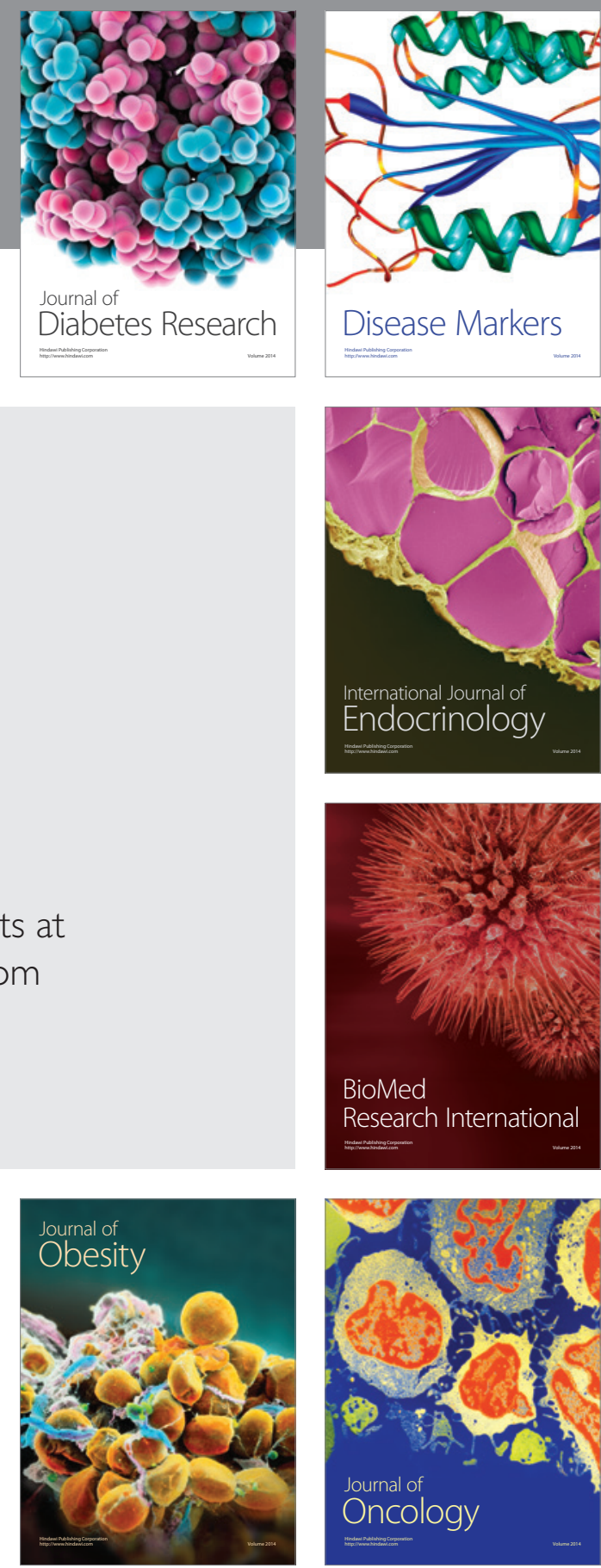

Disease Markers
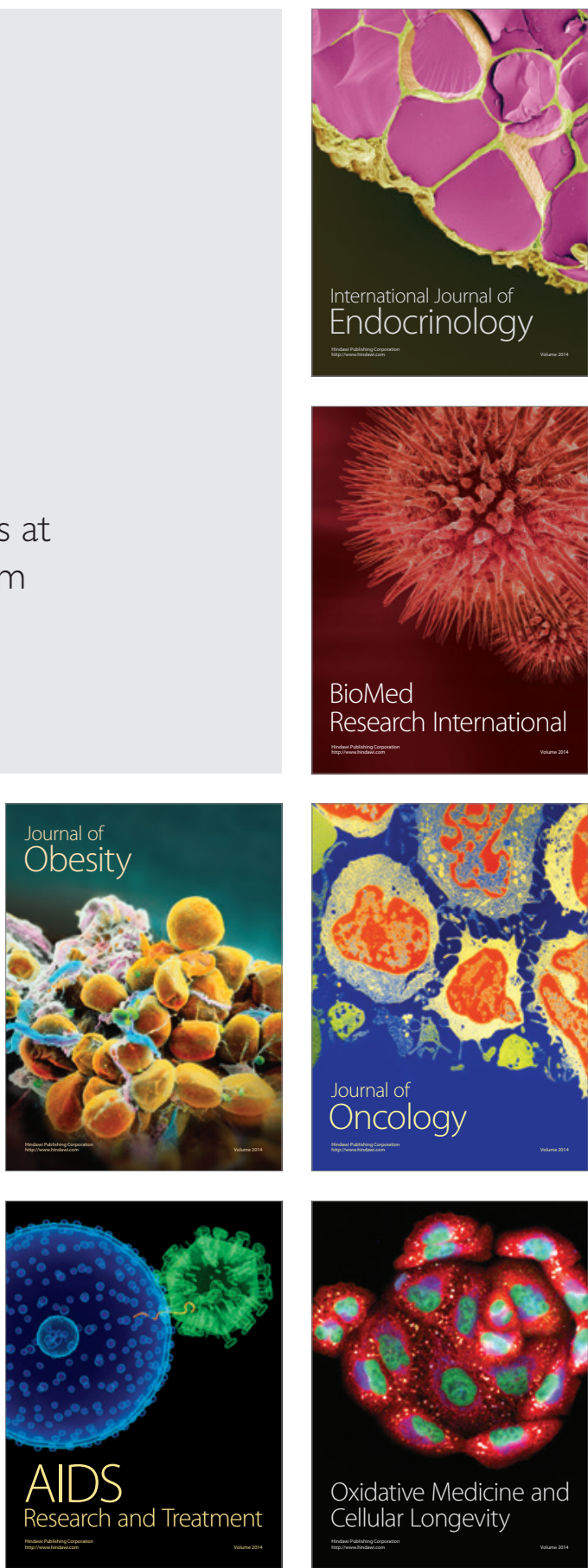